\title{
Introducing Discussion into Multilingual Mathematics Classrooms: An Issue of Code Switching?
}

\author{
Lyn Webb and Paul Webb \\ Nelson Mandela Metropolitan University, Port Elizabeth \\ lyn.webb@nmmu.ac.za \& paul.webb@nmmu.ac.za
}

\begin{abstract}
The Department of Education in South Africa advocates collaborative and constructivist learning; however, observations indicate that little discussion occurs in most multilingual mathematics classes. In this paper we draw on a pilot study set in the Eastern Cape where teachers were introduced to the theory and practice of exploratory talk, and then tasked to perform an action research project on introducing discussion in their own multilingual mathematics classrooms. The results of the study suggest some successes in terms of teachers initiating exploratory talk and highlight the fact that these successes were only achieved where code switching between English and isiXhosa formed an integral part of the process.
\end{abstract}

This study focuses on an intervention aimed at introducing teachers to the concept and practice of exploratory talk in their mathematics classrooms. The rationale for an exploratory talk approach is that it has been claimed that working in groups and talking with other learners leads to the development of mathematical reasoning (Mercer \& Sams, 2006), and the fact that, despite learners often being seated in groups in South African classrooms, very little meaningful discussion takes place (Taylor \& Vinjevold, 1999). The research aimed at investigating whether an intervention of this type could enable teachers to implement exploratory talk and, if so, what strategies teachers used to initiate the approach within their context of multilingual teaching and learning of mathematics.

In rural areas of the Eastern Cape (where this study took place) almost all schools choose English as the Language of Learning and Teaching (LoLT) despite the fact that the vast majority of the teachers and learners are isiXhosa main language speakers (Webb \& Treagust, 2006). Access to English in most of these schools is severely limited and there is little chance of many learners hearing English outside the school premises (Alidou et al., 2006). Classroom observation studies conducted in several countries in Africa (Benin, Burkina Faso, Guinea-Bissau, Mali, Mozambique, Niger, South Africa, Togo, Tanzania, Ethiopia, Ghana, and
Botswana) reveal that the use of an unfamiliar language, such as English, often results in traditional and teacher-centred teaching methods, e.g. chorus teaching, repetition, memorization and recall (Alidou et al., 2006). Setati and Adler (2001) have also shown that when teachers use English mainly for explanation, rote learning of procedures takes place and opportunities for developing meaningful learner-centred talk and writing are limited. This situation has important implications as studies by Mercer and Sams (2006) and others (e.g., Monaghan, 2004; Rojas-Drummond \& Fernandez, 2000; Wegerif, Littleton, Dawes, Mercer, \& Rowe, 2004) have shown that discourse plays a profound role in the construction of knowledge and reasoning.

In their pioneering work into mathematics teaching in multilingual classrooms in South Africa, both Adler and Setati have uncovered many 'dilemmas and contradictions' that teachers have to face in their dual role when teaching proficiency in English as well as mathematical concepts in the mathematics classroom (Adler, 2001; Setati, 1998). However, little research has been undertaken in the Eastern Cape where there is a widespread isiXhosa/English tension in the classroom. The paucity of data in this particular setting, and Adler's (2001) call to further study the various journeys that both teachers and learners make from 
informal talk in a main language to formal mathematics in another language, underpin the rationale for this study which is located within Mercer's (1995) socio-cultural framework and notions of the role of language and discourse in the development of mathematical reasoning.

\section{Classroom talk}

Classroom talk in general has been studied extensively over the past few decades and it appears that the most common kind of classroom interaction that takes place is the InitiationResponse-Feedback (IRF) questioning cycle (Sinclair \& Coulthard, 1975). This type of classroom talk, where the teacher asks a question, the learner makes a simple statement as an answer, and the teacher responds - usually simply to agree with the answer or reject it - has been criticised as a means of keeping control of the class by the teacher rather than a pedagogic tool (Webb \& Treagust, 2006). Furthermore, this type of communication leads learners to believe that mathematical knowledge is fixed, discovered and cannot be questioned (Barwell \& Kaiser, 2005). Most researchers in the field of classroom discussion reject this form of interaction and feel that it does not even qualify to be described as 'discussion'. Unfortunately in bilingual and multilingual South African classrooms, where learners are unable to express their reasoning in English, the IRF cycle abounds (Taylor \& Vinjevold, 1999) particularly in the Eastern Cape (Webb \& Treagust, 2006).

The dialogic perspective of learning is based on a Vygotskian viewpoint, i.e. that cognition is aided by cultural processes (Vygotsky, 1978). According to Barwell and Kaiser (2005) dialogism is 'practice-oriented' and communication is seen as an ongoing process of negotiation between people and contexts. A dialogic view of learning presumes that mathematics is created in the classroom through reasoning and argumentation between teacher-and-learner and learner-and-learner (Barwell \& Kaiser, 2005). In Eastern Cape classrooms, observation has shown that there is a paucity of explicit verbal argumentation between learner-and-learner. The approach used in this study emulates the strategy used by Mercer (1995) towards dialogic learning, i.e., understanding and encouraging learner talk and discussion so that their reasoning becomes visible.

According to Mercer (1995) talk between learners can be characterised into three main types and, if they are to enable their learners to successfully engage in meaningful discussions in the classroom, teachers need to be able to differentiate between them. Firstly, disputational talk is characterized by disagreements and individualized decision-making and where short assertions and counter-assertions are made. Secondly, cumulative talk takes place when learners build positively but uncritically on statements and assertions made by other learners (this talk is exemplified by repetitions, confirmations and elaborations). Finally, exploratory talk is actualised when learners engage critically, but constructively, with others' ideas, and justifications and alternate hypotheses are offered with joint consensus eventually being reached. Central to exploratory talk is the belief that collaborative thinking skills can be taught explicitly in order to enable both teachers and learners to understand talk as 'thinking aloud with others' (Monaghan, 2004). This resonates with the aims of the new South African curriculum, i.e. that collaborative and constructivist measures are important for meaningful learning to take place (Department of Education, 2003). Unfortunately exploratory talk, i.e. the type of discussion that is generally believed to best support constructivist learning, is the form of discussion least often heard in classrooms (Lemke, 1990).

In their study, Mercer and Sams (2006) attempted to raise learners' awareness of using language as a means of thinking together; to develop learners' abilities to use language as a tool for reasoning; and to apply language effectively in studying mathematics. The teachers in the experimental classes were trained in the introduction of exploratory talk in mathematics classrooms and were given detailed lesson plans to conduct. The learners in both their experimental and control classes were tested pre- and post-intervention using SATs mathematics items. In the experimental classes exploratory talk ground rules were negotiated with the learners. These ground rules were that: all relevant information must be shared; all members of the group should contribute to the discussion; all opinions and ideas must be respected and considered; everyone should be asked to make his/her reasons clear; challenges and alternatives must be made explicit and negotiated; and the team must seek to reach consensus (Mercer $\&$ Sams, 2006). They analysed transcripts of the learner discussions focusing on effective use of exploratory talk and showed that the learners in the target classes achieved significantly better in the post-test than the learners in the control classes (Mercer \& Sams, 2006). 
Multilingual classrooms and code switching

Teachers have voiced the difficulties they encounter when the LoLT is not the first language of either teachers or learners (Setati, 1998). This is also the case of many schools in the Eastern Cape where the learners are not exposed to English other than in their classrooms and teachers often use code switching in order to communicate with their learners (Taylor \& Vinjevold, 1999). In fact in many South African schools English can be considered to be more of a foreign language than an additional language (Adler, 2001). The lack of developed basic interpersonal communication skills (BICS) in English means that the learners have little or no framework available to them within which to develop their cognitive academic language proficiency (CALP), not only orally, but also in terms of reading and writing (Cummins, 1984). The difficulties that teachers experience in their classes when developing BICS and then moving from using informal spoken language to formal oral and written mathematical language has been clearly recognised and emphasised by Setati, Adler, Reed and Bapoo (2002), and extensive research has been documented on code switching in South Africa (Adler, 2001; Setati, 1998).

Code switching is considered to be a tool which can provide spontaneous and reactive discussion of concepts by learners and teachers in their main language (Setati, 2007). According to Moshkovich (2007), a misconception about code switching is that it stems from a deficit model and is used when the speaker is unable to recall suitable words or phrases in the language being spoken. She disagrees, and promotes the view that code switching should rather be seen as a complex language practice which allows for the greater use of the main language while still using the official language of learning and teaching. In the Eastern Cape many teachers have expressed that they feel guilty when they code switch as they consider that they are depriving learners of exposure to English. This study aimed at increasing teachers' awareness of the benefits of code switching by immersing them in a situation where they use code switching themselves in order to solve problems.

\section{Methodology}

This pilot study took place within the framework of a BEd (Hons) programme offered by the NMMU and focussed specifically on a semesterlong module which, amongst other purposes, was developed to examine language practices of 134 in-service mathematics teachers who were studying at centres in Port Elizabeth, King William's Town, Mthatha, Kokstad, East London and Ngcobo. During workshops these teachers were introduced to classroom discussion (including code switching) and practised exploratory talk in groups while solving problems posed by the nonverbal and supposedly culture-free Raven's Progressive Matrices tests, as was done in Mercer, Wegerif and Dawes' (1999) study. The discussion generated by the teachers during this activity was video-taped and inspected by an English and Xhosa speaker in order to investigate how the teachers engaged in discussions and which language strategies they employed when doing so. The teachers were interviewed in focus groups after this process to establish their perceptions of the efficacy of the strategy. Finally, the participating teachers were tasked with conducting a mini action-research project on the development of exploratory talk in their own mathematics classrooms. The 134 action research assignments produced by the teachers were used to generate data on the type of discussion that had occurred in their classrooms and the strategies that they had used to enable their learners to participate.

\section{Results}

The data generated by this research revealed similar results to those found in Mercer and Sams' (2006) study in that teachers realised that if they provided guidance and practice in using language in order to express mathematical reasoning, learners could express themselves more effectively and that this aided them in solving mathematical problems. More specifically the data generated suggest that code switching has a positive influence on generating mathematical understandings and that developing exploratory talk is sometimes a slow process that requires guidance. Vignettes from the study, discussed below, give insights into the discussion processes that took place in classrooms.

\section{Code switching}

The video-taped data of teachers in discussion revealed that at almost all times they code switched, that is they used both English and isiXhosa in a single linguistic episode (Moschkovich, 2007). They used English when mentioning mathematical terms e.g. circle, rectangle, diagonal, etc. This suggests that they were more comfortable with mathematical terms in English than with the words in the mathematics register of their main language (Moschkovich, 
2007). The effects of code switching are reported within the 'vignettes' section of this paper.

\section{Developing exploratory talk}

At first it appeared that the teachers found it difficult to differentiate between the different types of 'talk'. In all centres, initially, the teacher who felt $\mathrm{s} /$ he knew the correct answer would dominate the discussion (leading to cumulative talk). If there was disagreement, the most forceful character would prevail (disputational talk). Often the facilitator had to intervene to remind the teachers that the outcome was to experience the different types of 'talk' and not only to find the correct answer. In most cases the teachers eventually arrived at a situation which may be described as exploratory talk, i.e. they engaged with others' ideas and justifications and (to varying degrees) joint consensus was reached.

Many of the teachers reflected positively during the interviews on the understanding that they had achieved through using the tenets of exploratory talk and the ground rules based on those of Mercer and Sams (2006), e.g. that all information must be shared; groups must try to reach agreement; good reasons must be given for decisions; and everyone must be encouraged to speak. In discussions at all centres the teachers agreed that it would have been much more difficult to formulate solutions to the Raven's Test items individually than by discussing their reasoning in groups, suggesting that they had experientially discovered the benefits of sharing their reasoning with their peers. When questioned about their own code switching and the practice of code switching in their classrooms the teachers agreed that the strategy is commonly used in their classrooms to overcome both teachers' and learners' lack of fluency in English, but that it is accompanied by a sense of guilt and inadequacy as they feel that they have had no official guidance or stamp of approval from the Department of Education for the practice. They also expressed the fear that by using code switching they are depriving their learners of opportunities associated with the use of English.

Many of the interviewees also noted that they found it difficult to engage in exploratory talk in problem solving groups. This they attributed to the fact that they had never before thought about discussion or the quality of their interactions. They were able to identify that their first attempts had resulted in instances of disputational and cumulative talk and they recognised that they had had to be continually reminded by the facilitator of the ground rules that they had previously discussed and accepted, particularly the practice that each participant should be free to contribute and be encouraged to do so. This bears out Mercer and Sam's (2006) claim that it is necessary to provide guidance about, and practice in, using language effectively as a tool to enhance mathematical reasoning. When introducing exploratory talk into the classroom the teachers noted that their learners had to be coached constantly as practising the agreed upon ground rules did not come naturally to them (Mercer \& Sams, 2006).

\section{Classroom vignettes}

The action research assignments produced by the teachers were of a varied standard but in approximately $65 \%$ of cases it was possible to detect through the vignettes the type of classroom discussion promoted by the teachers (a compulsory aspect of the assignment). The following are two vignettes, as described in two different teachers' action research assignments, which give some insight into the different types of conversations that were generated when groups of learners discussed mathematical problems in English only, and when allowed/encouraged to use their home language.

The first is based on learners' conversation when attempting to solve the following word problem in English only:

There are 21 cycles in a shop. Some are bicycles and some are tricycles. If there are 51 wheels altogether, how many are bicycles and how many are tricycles?

Lethu: Do we all understand?

Limpho: What?

Lethu: What the teacher said.

Maria: Let's find the number of bicycles and tricycles.

Lethu: But how can we, if we talk?

Maria: This is easy, you see.

Limpho: What?

Maria: 24 bicycles and 1 tricycle.

Limpho: What?

Lethu: Did we talk - or did you just tell us?

Bongo: Yes, Maria is right. I can see 24 bicycles will be having 48 wheels $n e h$ ! Plus three for the tricycle.

Maria: That's all there is!

Lethu: Okay.

Maria: Do you all see? (Murmurs of assent) 
Of the ten learners present only four participated in the exchange, with only Maria and Bongo addressing the question. Maria suggested an answer which was flawed and resulted in an incorrect answer as they were focussing on the number of wheels only and not the restriction that there were 21 cycles in the shop, yet the other learners agreed without engaging in the reasoning themselves. They felt they had found a feasible answer and did not try to find alternative solutions. Their discussion was an example of cumulative talk, where one assertive participant's view was ratified by the other members of the group without reasons or explanations or counter arguments.

When the teacher asked the learners in this group about the low level of participation, one replied, "Siyasibamba isiNgesi!" ["The English is restricting us!"]. The teacher commented that when the learners were engaging in talk using only English they had difficulty in expressing their ideas and reasoning, and that the few learners in the group who were proficient in English dominated the conversation.

The second is a vignette of discussion that took place when a group of learners were encouraged to discuss their reasoning in isiXhosa when investigating possible answers for the following problem:

A family of 5 people need to cross a river. They have a raft which can carry a maximum of 100 $\mathrm{kg}$. To save time they want to make as few trips as possible. Jabu's mass is $57 \mathrm{~kg}$. Khaba's mass is $85 \mathrm{~kg}$. Linda's mass is $38 \mathrm{~kg}$. Mandla's mass is $60 \mathrm{~kg}$ and Nandi's mass is $35 \mathrm{~kg}$.

Sipho: $\quad$ I think Linda should go in the boat with Jabu.

Lilian: Why?

Sipho: $\quad$ I think it is because kaloku imass yabo ngu $93 \mathrm{~kg}$ is less than $100 \mathrm{~kg}$.

James: $\quad$ Why don't sithathe uKhaba kuba ngoyena unzima? [Why don't we take Khaba first because he is the heaviest?]

Vuyo: Ibuye iboat? [How will the boat return?]

James: Oh! I see. Liyabona.

Vuyo: $\quad H o w$ about Nandi goes with Mandla then Nandi comes back?

Bongo: What then?

Sinovuyo: Then Nandi goes with Linda, then Linda comes back again then goes with Jabu, then comes back, then Khaba gets on alone, and Linda comes back and gets Nandi - and then go together.

Ntombizondwa: Perfect! Just the trip!

Mcebisi: $\quad$ So can I report to the rest of the class?
Most of the learners in the group were prepared to express views and were prepared to offer challenges. The exploratory talk trigger words "why", "I think" and "because" were consciously used in this short episode by a number of the participants.

Other vignettes were provided by teachers in their action research assignments which could be judged to represent exploratory talk, but what was noticeable was that in all of these cases the learners engaged in code switching. In none of the cases reported where English only was used did the participants evolve their discussions further than cumulative talk.

\section{Discussion and implications}

There have been a number of studies which maintain that social activity through exploratory talk between peers in the classroom increases reasoning skills (Mercer \& Sams, 2006; Monaghan, 2004; Wegerif et al., 2004). RojasDrummond and Fernandez (2000) worked with English as additional language (EAL) primary school children in Mexico, while Webb and Treagust (2006) worked with isiXhosa-speaking learners in science classrooms in South Africa. The findings of both of these studies positively link teaching learners' explicit language use with enhanced reasoning skills. In both studies the learners who had been taught exploratory talk principles and used code switching in classes achieved better results on tests of non-verbal reasoning than those in the control classes who had not.

In this study teachers were exposed to the tenets of exploratory talk experientially and verbalised their preference for using their main language when grappling with a problem solving situation. In groups where there was a non-isiXhosa speaking teacher, the discussion was in English as the teachers felt that common understanding was important. When mathematical problems were discussed the teachers code switched, using words like "parallel" and "diagonal" in English whereas their reasoning was expressed in isiXhosa. They carried this positive experience through to their classrooms and realised that discussion flowed easier when they allowed their learners to use the vernacular, moreover results seemed more meaningful to the learners. Both teacher-learner and learner-learner interaction increased and instances of IRF questioning cycle were diminished. 
It has been noted that mathematics teachers can play an important role in the development of learners' awareness and use of language as a tool for reasoning, as well as for producing a more collaborative and inclusive classroom ethos (Mercer \& Sams, 2006). In addition, Barwell (2005) argues that policymakers and mathematics educators have stressed the difference between the precise subject language of mathematics and the more informal talk that learners use in the mathematics classrooms, and he feels that this has had a detrimental effect on inducting learners into mathematical practices. Furthermore, Barwell and Kaiser (2005) argue that if learners can be encouraged to talk informally about their mathematical reasoning there is more chance that they will be able to develop formal mathematical discourse. The results of this study concur with this viewpoint as they indicate that when teachers do not emphasise the use of 'English only', informal discussion increases. Without a culture of informal talk using BICS, there is little possibility of developing mathematical discourse in CALP and so the journey is truncated before it is even begun.

One of the teachers used the metaphor of her experience of learning to drive a car. When she was concentrating on the skills of gear changing and braking she had no confidence in her ability to drive in public. It was only when the skills became transparent, or second nature to her, that she was able to shift her focus onto driving effectively. In her class she has tried to make language transparent so that the learners can focus on mathematical reasoning rather than on the language used. This has resulted in greater use of the vernacular together with code switching, and an increase in classroom discourse. In this particular teacher's classes she has introduced a culture of argumentation through exploratory talk, which supports dialogic learning. It is hoped that continued use of these practices will result in progress from informal talk in isiXhosa to the development of mathematical discourse in English.

The results of the classroom research reports indicate that some teachers consider that any discussion in groups constitutes exploratory talk, in the same way that some teachers feel that seating learners in groups constitutes collaborative learning. This resonates with Mercer ands Sams (2006) caveat that on-going training is necessary to sensitise both teachers and learners to the nuances of the different types of talk so that the tenets of exploratory talk can be practised. As such, it seems that practical, meaningful and appropriate sociocultural mathematics cum language interventions, which include exploratory talk and code switching, need to be developed, implemented and researched if more and more learners are not to become marginalized in multilingual classrooms because of limited language acquisition.

\section{References}

Adler, J. (2001). Teaching mathematics in multilingual classrooms. Dordrecht: Kluwer Academic Publishers.

Alidou, H., Boly, A., Brock-Utne, B., Diallo, Y., Heugh, K., \& Wolff, H. (2006). Optimizing learning and education in Africa - The language factor. A stock-taking research on mother tongue and bilingual education in Sub-Saharan Africa. Gabon: Unesco Institute for Education.

Barwell, R. (2005). Ambiguity in the mathematics classroom. Language and Education, 19(2), 118-126.

Barwell, R., \& Kaiser, G. (2005). Mathematics education in culturally diverse classrooms, $Z D M$, 37(2). 61-63.

Cummins, J. (1984). Wanted: A theoretical framework for relating language proficiency to academic achievement among bilingual students. In C. Rivera (Ed.), Language proficiency and academic achievement. Clevedon: Multilingual Matters.

Department of Education, (2003). National curriculum statement grades 10-12 (General), Mathematics. Pretoria: Government Printers.

Lemke, J. (1990). Talking science: Language, learning and values. New Jersey: Ablex.

Mercer, N. (1995). The guided construction of knowledge: Talk amongst teachers and learners. Clevedon: Multilingual Matters.

Mercer, N., \& Sams, C. (2006). Teaching children how to use language to solve maths problems. Language and Education, 20(6), 507-528.

Mercer, N., Wegerif, R., \& Dawes, L. (1999). Children's talk and the development of reasoning in the classroom. British Educational Research Journal, 25(1), 95-110.

Monaghan, F. (2004). Thinking together - using ICT to develop collaborative thinking and talk in mathematics. In O. McNamara (Ed.), Proceedings of the British Society for Research into Learning Mathematics, 24(2), 69-74.

Moschkovich, J. (2007). Using two languages when learning mathematics. Educational Studies in Mathematics, 64(2), 121-144.

Rojas-Drummond, S., \& Fernandez, M. (2000). Developing exploratory talk and collective reasoning among Mexican primary school children. Proceedings of III Conference for Sociocultural Research. Sao Paulo, Brazil. 
Setati, M. (1998). Code switching in a senior primary class of second language learners. For the Learning of Mathematics, 18(1), 34-40.

Setati, M. (2005). Teaching mathematics in a primary multilingual classroom. Journal for Research in Mathematics Education, 36(5), 447-466.

Setati, M. (2007). Towards pedagogy for teaching mathematics in multilingual classrooms in South Africa. Paper presented at the second Marang symposium on teaching and learning mathematics in multilingual classrooms. University of the Witwatersrand, Johannesburg.

Setati, M., \& Adler, J. (2001). Between languages and discourses: Language practices in primary mathematics classrooms in South Africa. Educational Studies in Mathematics, 43(3), 243269.

Setati, M., Adler, J., Reed, Y., \& Bapoo, A. (2002). Incomplete Journeys: Code switching and other language practices in mathematics, science and English language classrooms in South Africa. Journal of Language Education, 16(2), 128-149.
Sinclair, J., \& Coulthard, R. (1975). Towards an analysis of discourse. Oxford: Oxford University Press.

Taylor, N., \& Vinjevold, P, (1999). Getting learning right. Report of the President's Education Initiative Research Project. Johannesburg: Joint Education Trust.

Vygotsky, L. (1978). Mind in society: The development of higher psychological processes. Cambridge, MA: Harvard University Press.

Webb, P., \& Treagust, D. (2006). Using exploratory talk to enhance problem solving and reasoning skills in grade 7 science classrooms. Research in Science Education, 36, 381-401.

Wegerif, R., Littleton, K., Dawes, L., Mercer N., \& Rowe, D. (2004). Widening access to educational opportunities through teaching children how to reason together. Westminster Studies in Education, 27(2), 143-156. 